SECTION 19. Management. Marketing. Public administration

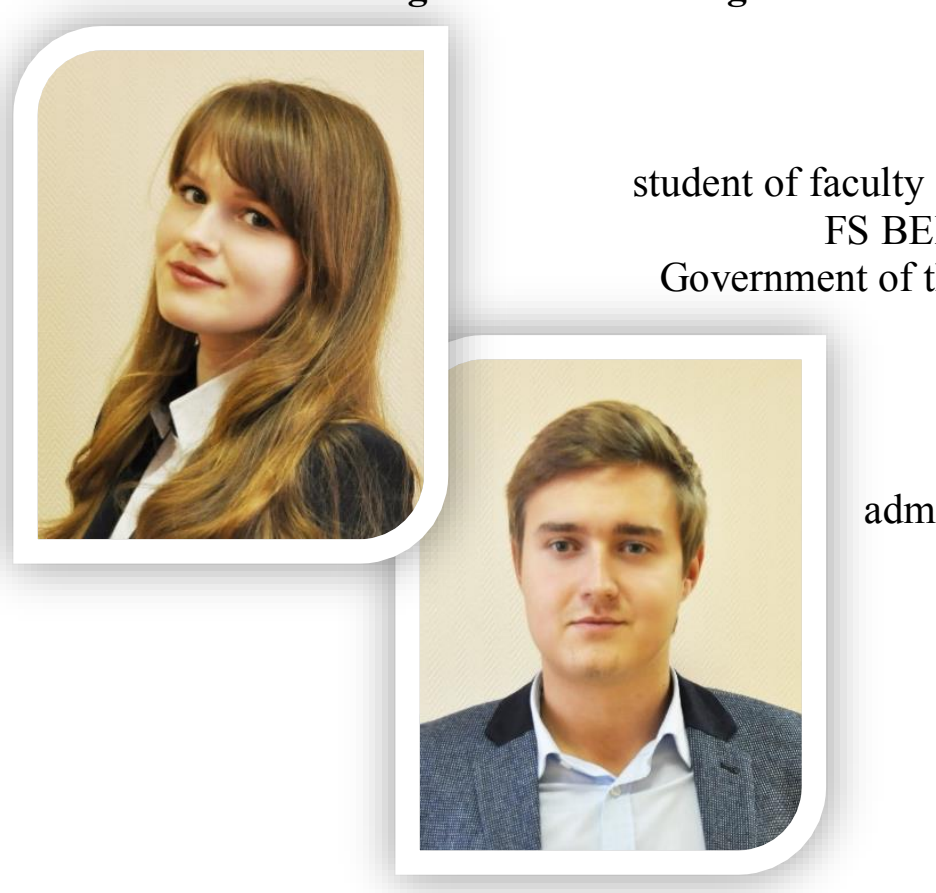

Anastasia Igorevna Dunaeva (Public and municipal administration" of S BEI of HPE "Financial University under the Government of the Russian Federation", Russia, Moscow nastia007.07@mail.ru

Nikita Olegovich Udachin student of faculty "Public and municipal administration" of FS BEI of HPE "Financial

University under the Government of the Russian Federation", Russia, Moscow

\title{
PROBLEMS AND PROSPECTS OF SMALL BUSINESS IN RUSSIA TODAY
}

Abstract: In the last 10-15 years, the activities of small enterprises has attracted the attention of researchers, scientists, economists and politicians in different countries. This is due to the fact that the small business sector makes a significant part of the GDP of many countries ( developed countries from 30 to $60 \%$ ), making a significant contribution to solving the problems of employment and competitiveness of entire industries. In connection with this, the interest of economists to study the growth of small businesses, to the analysis of the methods and means of state support for this sector.

Key words: small business, problems of small business, enterprise, business

\section{ПРОБЛЕМЫ И ПЕРСПЕКТИВЫ РАЗВИТИЯ МАЛОГО БИЗНЕСА В РОССИИ НА СОВРЕМЕННОМ ЭТАПЕ}

\begin{abstract}
Аннотация: В последние 10-15 лет деятельность мальх предприятий привлекает к себе внимание исследователей, ученых-экономистов и политиков в различных странах. Это связано с тем, что сектор малого бизнеса производит значительную часть ВВП многих стран (в развитых странах от 30 до 60\%), вносит существенный вклад в решение проблем занятости и повышения конкурентоспособности цельх отраслей. $B$ связи $c$ этим понятен интерес экономистов к изучению особенностей развития малого бизнеса, к анализу методов и средств государственной поддержки данного сектора экономики.
\end{abstract}

Ключевые слова: мальй бизнес,проблемы малого бизнеса, предприятия, предпринимательство.

Переход к рыночным отношением негативно сказался на экономике нашей страны, принеся с собой большой круг проблем. Решение данных проблем включало в себя определение прав собственности, т.е. принять решение, кому будут переданы во владение предприятия, которые находятся в государственной собственности и выбрать механизм и цены, по которым будет осуществляться передача прав собственности. 
Необходимо было также сформировать рынки капитала, финансовую, валютную и банковскую системы. Разработка эффективных систем планирования и прогнозирования, а также бухгалтерского учета была необходимым условием для проведения стоимостной оценки предприятий и возможности объективного суждения о результативности их деятельности. Пересмотр законодательства был важен для легализации новых форм экономических взаимоотношений и типов собственности. Также основным требованием были подбор и обычение специалистов в области управления, которые были бы способны осуществлять свою деятельность в новых условиях по ведению конкурентной борьбы на территории своей страны и зарубежом.

Задача выработки политики в сфере конкуренции и регулирования и поиск способа урегулирования проблем, которые возникали вследствие приватизации крупнейих предприятий, которые не обладали достаточной эффективностью, стояла наиболее остро, так как возникала угроза возникновения крупных и неээфективных предприятий - монополистов.

Органам государственной власти было крайне необходимо определить порядок, в соотвтствии с которым государство прекращало бы процесс субсидирования и организовать систему налогов, которая была бы способна обеспечить финансовую деятельность государства.

Завершающим этапом было решение проблемы о возможности и сроках закрытия фирм, которые не обладали достаточной конкурентоспособностью и сформировать специальные службы, осуществляющие социальную помощь и решающие социальные проблемы, которые возникают из - за неизбежности экономической непропорциональности.

Большая доля этих проблем в полной мере приходится на малый бизнес. Сейчас проблемы, препятствующие активному развитию малого предпринимтельства в нашей стране, полностью совпадают с теми проблемами, которые былт отмечены во время 1го Всероссийского съезда представителей малых предприятий, а именно:

$>\quad$ отсутствие достаточного количества стартового капитала и оборотных средств у малых предприятий;

$>\quad$ сложный процесс получения заемного капитала;

$>\quad$ негативное влияние со стороны криминальных структур;

$>\quad$ дефицит работников, обладающих необходимой квалификацией;

$>\quad$ трудности в аренде производственных площадей (высокая плата за аренду);

$>\quad$ ограниченность в получении услуг лизинговых компаний;

$>$ отсутсвие системы социальной безопасности для владельцев и работников малых фирм [2].

По данным специалистов, которые проводили анализ оборота теневой экономики, известно, что на долю предприятий, занятых в такой сфере приходится около 40\% валового национального продукта (ВНП)[7].

Некоторые авторы считают правильным рассматривать данные проблемы с учетом степени их важности, а именно в таком порядке:

1. высокие ставки по налогам;

2. трудности в получении заемного капитала;

3. административные препятствия[3].

Как можно увидеть из перечня проблем,представленного выше, на второе место отнесли проблемы, связанные с труднодоступностью финансовых средств, а именно замемного капитала. Председатель правления Федерального фонда поддержки малого предпринимательства А.В. Рунов приводить следующие данные о доступности малых предприятий к финансовым ресурсам: каждый год около 15 тысяч предприятий малого бизнеса имеют возможность получить финансовые ресурсы в банке. Из этого можно 
сделать вывод, что в нашей стране доля рынка, охваченная представителями банковской системы, составляет лишь $1 \%$.

Осуществляя свою деятельность, представители малого бизнеса сталкиваются с целым рядом трудностей. Главная из них - недостаточность ресурсной базы, как в материально - техническом, так и в финансовом плане. В данном случае говорится о возможности создания новой сферы экономики, которая отсутствует в нашей стране вот уже в течение нескольких десятилетий, что означает также и отсутствие квалифицированных и опытных предпринимателей. Большинство начеления просто не могло начать свое дело, так как из - за не большой заработной платы у них отсутствовала возможность для накопления достаточныого количества средств[5]. В данной ситуации предельно ясным является тот факт, что источником таких средств государственных бюджет стать не может ввиду отсутствия у него такой возможности,которая обусловена его напряженностью. Единственным выходом из данной ситуации остается банковская система с ее кредитными ресурсами. Но как известно их также не хватает, а в купе с инфляцией они становятся крайне трудно реализуемы.

Следующей проблемой является несовершенство действующего законодательства в области регулирования деятельности представителей алого и среднего бизнеса. Трудность также же заключается в отсутствии единой законодательной базы в сфере регулирования деятельности малого и среднего бизнеса, а также имеющихся разрозненных установлениях, которые претворяются в жизнь, но далеко не полностью.

На данный момент малый бизнес находится в таких условиях, которые весьма отдаленны от тех, что должны быть присущи рыночным отношениям. Кроме того, ощущается тенденция к тому, чтобы все больше окружать его старыми рамками планово-административной системы с ее практически всеохватным планированием и жесткой регламентацией с помощью лимитов, фондов и т.п.

Отсутствует система проведения глубокого анализа деятельности предприятий малого бизнеса, нет надлежащего учета результатов их работы, практически отсутствует отчетность по тем показателям, которые дают право этим предприятиям воспользоваться льготами по налогообложению.

Материально-техническое обеспечение предприятий малого бизнеса осуществляется в несвоевременно и в недостаточном объеме. Отсутствуют машины, оборудование, приборы, предназначенные для таких предприятий и учитывающие их специфику. Для них ограничен доступ к высоким технологиям, так как их покупка означает значительные одноразовые финансовые затраты.

Еще одна проблема - кадровая. В настоящее время в экономике гораздо меньше квалифицированных предпринимателей, чем действительно нужно.

Непростой проблемой является социальная защита предпринимательской деятельности. Известно, что в настоящее время практически подорвана ранее существовавшая на основе распределения общественных фондов система социальных гарантий и социального обеспечения. Следовательно необходимо начать с нуля при постройке данной системы по отношению ко всему обществу, и тем более по отношению к предпринимателям, как к новому социальному слою.

Существенной проблемой для малого бизнеса является обеспечение доступа к производственным площадям и офисным помещениям. Такие площади во многих регионах либо в большом дефиците и, как следствие, - запредельно дороги, либо их приобретение или аренда сопряжены с необходимостью преодолевать нередко искусственные административные барьеры. 
Другой проблемой развития малого бизнеса в России, выявленной в ходе исследования является взаимодействие предпринимателей с местными властями и проверяющими инстанциями.

Практический опыт работы по формированию и реализации комплексных программ социально-экономического развития взаимодействия власти и бизнеса в муниципалитетах показал, что их эффективной реализации препятствуют: отсутствие гарантий покрытия издержек частного предпринимателя; недоверие бизнеса и населения ко всем институтам власти; административные барьеры, создаваемые налоговой инспекцией, полицией и мэрией города; осложненный доступ к производственной инфраструктуре; низкие доходы населения; отсутствие привлекательных заемных ресурсов и незаинтересованность в участии в муниципальном заказе.

Можно утверждать, что основными причинами, препятствующими эффективному взаимодействию власти и бизнеса на муниципальном уровне являются неосведомленность (неинформированность) в общих вопросах межсекторного взаимодействия и неумение сотрудничать, а также несовершенная нормативно правовая база.

И все же главная проблема малого бизнеса - недостаток как собственного стартового капитала, как и капитала для развития. Низкие возможности отдельных кредиторов по распределению и принятию рисков, связанных с невозвратом кредитов, и долгосрочное отвлечение значительных банковских ресурсов на сделки преимущественно спекулятивного характера (например, с государственными ценными бумагами) приводят к ограничению числа бизнес-проектов, которые могли бы получить финансирование. Это, естественно, тормозит развитие малых предприятий.

Для изменения подобной ситуации необходимо проводить комплексную программу поддержки малых предприятий, создавать и популяризировать единое информационное пространство для органов власти и предпринимателей, упрощать законодательство и снижать административные барьеры[10].

Малый бизнес играет достаточно важную роль в рыночной экономике. Прежде всего, он придает необходимую гибкость рыночной экономике в целом за счет оперативной реакции на изменение конъюнктуры рынка, а также способствует развитию конкурентной среды и тем самым снижению степени монополизации экономики. В силу своих небольших размеров и многочисленности, малый бизнес намного труднее монополизировать, чем массовое производство на крупных предприятиях.

Следовательно, трудно переоценить значимость развития малого бизнеса, в каких сферах он способен коренным образом и без существенных капитальных вложений расширить производство многих потребительских товаров и услуг и обеспечить достижение целевых показателей экономического роста. Малое предпринимательство способствует развитию предприимчивости, практически дает возможность каждому человеку проявить себя, воплотить свои идеи в жизнь.

Исследование проведено под руководством: к.э.н., доцента, Бутовой Татьяны Витальевны, заместителя декана факультета «Государственное и муниципальное управление» ФГОБУ ВПО «Финансовый университет при Правительстве Российской Федерации».

\section{References:}

1. № 209-Ф№ от 24.07.2007 «О развитии малого и среднего предпринимательства в Российской Федерации» 
2. Г.Н. Франовская. МАЛЫЙ БИЗНЕС. Учебное пособие для вузов. 2007

3. Горфинкель В.Я. Малый бизнес. Организация, экономика, управление. Учеб. Пособие - М: ЮНИТИ-ДАНА,2009 .-495с.

4. Романов А.Н. Предпринимательство. М: ЮНИТИ-ДАНА, 2012. -687c.

5. Кузнецов В.В. Бизнес-план создания малого предприятия. Экономические методы управления предпринимательской деятельностью., Электронная Библиотека УлГТУ

6. Малое предпринимательство: организация, экономика, управление: Учеб. Пособие / под ред. А.Д.Шеремета.- М:ИНФРА-М, 2009

7. Российский статистический ежегодник. 2011: Стат.сб./Росстат. - М., 2011. - 795 с.

8. Экономика фирмы : учеб. пособие / [под ред. Н.П. Иващенко]. М. : ИНФРА, 2006. $528 \mathrm{c}$.

9. Институциональные аспекты организации малого бизнеса в развитых странах и в России. В.А. Рубе, Учеб. пособие. - М.: ИНФРА-М, 2004. - 79 с.

10. Просветов Г.И. Управление малым бизнесом. Задачи и решения: Учебнопрактическое пособие. - М.: Альфа-пресс, 2010. - 320 с. 